\title{
Is there a safe and effective way to wean patients off long-term
} glucocorticoids?

\author{
Baker E H
}

Affiliations: Clinical Pharmacology and Therapeutics Section, Institute of Medical and Biomedical Education; Institute for Infection and Immunity, St George's, University of London; and Clinical Pharmacology Group, Pharmacy and Medicines Directorate, St George's University Hospitals NHS Foundation Trust, London

Correspondence: Professor Emma H Baker, Mailpoint J1A, First Floor Jenner Wing, St George's, University of London, Cranmer Terrace, London SW17 ORE

Email: ebaker@sgul.ac.uk Tel: 07714216417

Running head: Deprescribing systemic glucocorticoids

Keywords: Glucocorticoids, adverse drug reactions, dose-related, withdrawal, inflammatory disease, adrenal insufficiency 


\begin{abstract}
Glucocorticoids are highly effective medicines in the treatment of inflammatory disorders. However they cause severe adverse reactions, particularly where taken at high doses systemically for prolonged periods. Systemic glucocorticoids are therefore given at dosage sufficient to control the disease, then withdrawn as fast as is possible to minimise dose- and time-related adverse drug reactions without losing disease control. Adverse withdrawal reactions present a major challenge in the withdrawal of long term glucocorticoids. Suppression of the hypothalamic-pituitary-adrenal (HPA) axis causes adrenal insufficiency, which is potentially life threatening and can become symptomatic as treatment is withdrawn. Adrenal insufficiency can be extremely difficult to differentiate from 'glucocorticoid withdrawal syndrome', where patients experience symptoms despite adequate adrenal function, and from psychological dependence.

Long term systemic glucocorticoids should therefore be withdrawn slowly. The rate at which the dose is tapered should initially be determined by treatment requirements of the underlying disease. Once 'physiological' doses are reached, the rate of reduction is determined by rate of HPA recovery and need for exogenous glucocorticoid cover while endogenous secretion recovers. If symptoms prevent treatment withdrawal, HPA testing should be used to look for adrenal insufficiency. Patients with adrenal insufficiency require 'physiological' doses of glucocorticoids for adrenal replacement, which may be lifelong if the HPA axis fails to recover.
\end{abstract}




\section{Introduction}

Medicines form an essential component of healthcare, relieving symptoms, curing and controlling disease and improving quality of life and survival. However, they do this at the cost of adverse drug reactions, which can have the opposite effects, causing symptoms and iatrogenic disease and reducing quality of life and survival. The challenge for health practitioners in prescribing and deprescribing is to optimise benefits while minimising risk. Glucocorticoids, as life-saving medicines that cure or control a wide range of diseases, but cause serious and sometimes life-threatening adverse effects, particularly exemplify this challenge. This review arose from a clinical pharmacology symposium that addressed 'Avoiding harms from overprescribing', so is focused on optimising the risk-benefit ratio for corticosteroids by safe and effective withdrawal, rather than on initiating treatment. It has been written from the perspective of a clinical pharmacologist and is intended for an audience interested in the principles of deprescribing.

\section{Glucocorticoids}

Glucocorticoids are commonly used for their anti-inflammatory and immunomodulatory properties in the treatment of a wide range of inflammatory, immunological, allergic and malignant diseases and in the prevention of graft rejection after transplantation. A recent population study from Denmark found that the annual prevalence of systemic (oral and injectable) glucocorticoid use was $~ 3 \%$, increasing to $6.7-7.7 \%$ in people $60-79$ years of age and to $9.7-11 \%$ in those $\geq 80$ years of age [1]. In 2018 in England, 8 million prescriptions for systemic glucocorticoids, 21 million prescriptions for inhaled glucocorticoids and 12 million prescriptions for topical glucocorticoids were dispensed in the community [2]. Glucocorticoids bind to glucocorticoid receptors, which are expressed in almost every cell in the body and have pleiotropic effects on multiple signalling pathways [3]. This makes them highly effective anti-inflammatory drugs, but also causes diverse serious adverse effects that limit their use.

\section{Adverse effects}

The DoTS classification system for adverse drug reactions [4] provides a useful framework for describing the adverse effects of corticosteroids and improving their management. This classification, proposed by the eminent clinical pharmacologists Jeff Aronson and Robin 
Ferner, is a three-dimensional system based on dose relatedness, timing and patient susceptibility. Figure 1 [5-13] attempts to map many of the adverse effects of glucocorticoids by the earliest time after treatment initiation against the lowest dose at which they have been reported to occur. Adverse reactions where the dose relatedness and timing of adverse effects is particularly variable due to differences in patient susceptibility (such as hyperglycaemia and hypokalaemia) are not included in this plot.

\section{$\underline{\text { Dose relatedness }}$}

Prolonged and/or high dose glucocorticoid therapy promotes gluconeogenesis, protein catabolism and lipolysis, reduces proliferation of actively dividing cells, promotes apoptosis, inhibits the synthesis of extracellular matrix proteins, has vasopressor effects and suppresses the hypothalamic pituitary axis [3]. Adverse effects of treatment explained by these mechanisms include: hyperglycaemia and diabetes mellitus; growth retardation and muscle loss; redistribution of fat (central obesity, moon face and buffalo hump); thin skin, easy bruising and poor wound healing; eye changes including ocular hypertension and cataracts; osteoporosis; increased susceptibility to infection; hypertension; and adrenal insufficiency. As glucocorticoids exert mineralocorticoid effects, they can cause fluid retention and hypokalaemia. Mechanisms underlying neuropsychiatric adverse effects, such as mood, emotional, behavioural and cognitive changes, are less well understood. Some toxicity from systemically administered (oral or injected) glucocorticoids is inevitable, even with short courses of treatment. However, the adverse effects experienced by an individual depend on both the average and the cumulative dose of treatment, with harms experienced even at very low doses of glucocorticoids when given over long periods of time (figure 1).

\section{$\underline{\text { Timing }}$}

Some adverse reactions to glucocorticoids occur early in therapy, whereas others occur later, with the risk increasing with duration of and/or repeated exposure (figure 1). Reducing the dose or withdrawing therapy can minimise the risk of dose-related adverse effects. However treatment withdrawal itself causes adverse effects, including adrenal insufficiency and a more non-specific glucocorticoid withdrawal syndrome. 
Adrenal insufficiency. The endogenous glucocorticoid, cortisol is secreted by the adrenal cortex at around $5.7 \mathrm{mg} / \mathrm{m}^{2} /$ day [14]. For adults, assuming an average surface area of $1.7 \mathrm{~m}^{2}$ [15], this equates to around $10 \mathrm{mg}$ of hydrocortisone per day at times of low physiological stress. Glucocorticoid release from the adrenal glands is regulated by the hypothalamicpituitary-adrenal (HPA) axis. In the hypothalamus, the circadian oscillator in the suprachiasmatic nucleus controls secretion of corticotrophin-release hormone (CRH) into hypophyseal portal veins. CRH stimulates the anterior pituitary gland to release stored adrenocorticotrophic hormone (ACTH) into the circulation and promotes synthesis of new ACTH. ACTH simulates cortisol secretion by the adrenal glands with a pronounced diurnal rhythm. Plasma cortisol concentrations peak at 06.00 to 07.00 am and reach a nadir at around 24.00 hours. Physiological and emotional stress override this daily rhythm, stimulating a rapid increase in cortisol levels. Cortisol exerts negative feedback on the hypothalamus and anterior pituitary gland, regulating secretion of $\mathrm{CRH}$ and $\mathrm{ACTH}$. Exogenous glucocorticoids suppress the HPA axis by reducing secretion and synthesis of $\mathrm{CRH}$ and ACTH, which in turn reduces endogenous cortisol production and secretion by the adrenal glands. After a short course of exogenous glucocorticoids HPA suppression can reverse rapidly [16]. However if treatment is prolonged, atrophy of corticotrophin cells in the anterior pituitary [17] and of the adrenal glands [18] may occur and HPA suppression may be prolonged over weeks [19], months or years [20].

In a systematic review of studies measuring adrenal function following systemic glucocorticoid exposure, Joseph and colleagues found that a median of $37 \%$ (interquartile range 13-63\%) patients had adrenal insufficiency [20]. Adrenal insufficiency occurred even with low dose ( $<5 \mathrm{mg}$ prednisolone equivalent) and short duration ( $<4$ weeks) glucocorticoid treatment and following tapered withdrawal. It persisted in $15 \%$ patients retested 3 years after glucocorticoid withdrawal. In a separate review, Broersen and colleagues found that there was no administration form, dosage, treatment duration or underlying disease for which adrenal insufficiency could be excluded, although increased dose and duration of treatment were associated with increased risk [21].

The clinical consequences of adrenal insufficiency include chronic symptoms and acute adrenal failure (Addisonian crisis) (table 1). Laugesen and colleagues recently conducted a Danish population-based self-controlled case series study using medical registries [22]. They 
investigated clinical indicators of adrenal insufficiency in patients before, during and after withdrawal of long term ( $\geq 3$ months) oral glucocorticoid treatment. They demonstrated a real clinical impact of adrenal insufficiency in these patients, with risks of hypotension, gastrointestinal symptoms, hyponatremia, and hypoglycemia being increased in the glucocorticoid withdrawal period and, for hypotension and gastrointestinal symptoms, persisting over the subsequent 7 months.

\section{Glucocorticoid withdrawal syndrome}

Glucocorticoid withdrawal syndrome is defined by symptoms that develop as glucocorticoid therapy is withdrawn, despite normal HPA function. These symptoms can be similar to the chronic symptoms of adrenal insufficiency, which makes it difficult to tell the two conditions apart (table 1). One distinguishing feature is that glucocorticoid withdrawal syndrome can be symptomatic even at supraphysiological glucocorticoid doses, whereas adrenal insufficiency is controlled by physiological doses.

Inherent in the description of glucocorticoid withdrawal syndrome is the implication that patients become dependent on or 'addicted to' glucocorticoids, accounting for both physiological and psychological discomfort when treatment is withdrawn [23]. Glucocorticoids have pleiotropic effects, altering many different pathways and mediators, which could contribute to development of dependence. Candidates include $\mathrm{CRH}$, vasopressin, pro-opiomelanocortin and the adrenergic system [24]. In the brain, exogenous glucocorticoids may alter neurotransmitters [23] and impair recovery from neuronal damage [5]. It is well recognised that patients taking glucocorticoids can develop neuropsychiatric effects including psychotic reactions, as well as changes in mood, cognition, memory and/or behaviour [5]. Neuropsychiatric effects including depression, delirium, confusion or disorientation, non-psychotic mania and panic disorder have also been reported during dose reduction [25] and may complicate treatment withdrawal. Glucocorticoids have been implicated as a driver of addictive behaviour [26] and occasionally are used as drugs of abuse [27]. Anfinson and colleagues identified 22 cases of glucocorticoid dependence on a MEDLINE search that met criteria for DSM I-IV substance dependence [27]. They commented that glucocorticoids may induce dependence through their propensity to induce euphoria and by directly influencing reward circuitry, as well as through physical dependence. 


\section{Patient susceptibility}

Although more than $90 \%$ of people taking long term glucocorticoids experience at least one adverse reaction, effects vary between individuals. For example, of 2446 patients taking $16 \pm 14 \mathrm{mg}$ prednisolone for $284 \pm 177$ days, $70 \%$ reported weight gain, $15 \%$ experienced cataracts and $12 \%$ had a fracture [7]. Much of this interindividual variability is explained by differences in cumulative and average glucocorticoid dose, but individual patient susceptibility to adverse effects may play a role. Mechanisms include pharmacodynamic factors affecting the response to glucocorticoids and pharmacokinetic factors affecting glucocorticoid exposure. For example the N363S polymorphism of the glucocorticoid receptor gene is associated with increased sensitivity to exogenous glucocorticoids, increased body mass index and reduced spinal bone mineral density [28]. Concomitant administration of glucocorticoids with drugs that inhibit cytochrome P450 3A4 may increase glucocorticoid exposure and adverse events.

Inhaled and topical corticosteroids

Inhaled and topical routes of administration are used for glucocorticoid treatment of respiratory, ENT, dermatological and ophthalmological conditions to limit systemic exposure. Significant systemic adverse effects of these therapies are therefore unusual, although sporadic reports - usually due to drug interactions - occur with sufficient frequency to deserve a mention here [e.g. 29]. Clinically significant adverse reactions to inhaled or topical corticosteroids generally are (DoTS classification):

- Dose related - caused by high doses of high potency glucocorticoids (table 2 [30-32])

- Time related - occur in patients who are on long term treatment

- Susceptibility - risk is increased by factors that increase bioavailability of inhaled or topical glucocorticoids. Drug absorption can be increased by inflammation of airways or skin, increasing blood flow and epithelial permeability where drugs are applied. Drug clearance can be reduced markedly by interactions with drugs that inhibit cytochrome P450 3A4 e.g. cyclosporin, erythromycin, itraconazole and ritonavir.

\section{Challenges in managing glucocorticoid withdrawal}


Glucocorticoid therapy has the potential for considerable benefit through control of lifethreatening and/or disabling disease, but at the potential cost of considerable harms through adverse drug reactions that increase with dosage and duration of therapy. The goal of glucocorticoid therapy is therefore to obtain the maximum possible therapeutic benefit with the lowest possible average and cumulative dose to minimise adverse effects. In practice, this is achieved by starting glucocorticoid treatment at a moderate to high dose (e.g. $40 \mathrm{mg}$ prednisolone for an asthma exacerbation, 1000 mg methyl prednisolone for graft rejection reactions in transplantation or relapse in multiple sclerosis) to gain disease control, then withdrawing glucocorticoid treatment to as low dose as can be achieved while still maintaining disease control. Glucocorticoid withdrawal is greatly complicated by the emergence of symptoms, which may be a manifestation of disease reactivation, adverse reactions related to drug withdrawal (adrenal insufficiency, glucocorticoid withdrawal syndrome) and/or psychological dependence (figure 2). Distinguishing between these and supporting patients in successful withdrawal of glucocorticoids can be a considerable challenge.

Patient perception of glucocorticoids may affect their willingness to take treatment, with nonadherence leading to loss of disease control. Anecdotally many patients starting glucocorticoid treatment express fears of weight gain, skin changes and 'becoming addicted' with patients being particularly concerned where a relative has died from glucocorticoidrelated adverse effects. These anecdotes are borne out by studies of patient perceptions of glucocorticoid therapy, which found that patients voiced concerns about adverse effects [33] and, given a 'risk-free choice', preferred withdrawal of glucocorticoids over other agents [34]. It is essential that the benefits and risks of treatments and patient concerns are fully discussed before starting treatment and that the decision to undertake glucocorticoid treatment is made jointly by patient and practitioner. By contrast, patients established on glucocorticoid treatment can find it difficult to adhere to practitioner guidance to taper their treatment due to the emergence of physical or psychological withdrawal effects. A full discussion of the purpose of treatment withdrawal and close supervision and support, including objective disease measurements, can reduce glucocorticoid exposure [35].

Some of the challenges of glucocorticoid withdrawal and discussion of how to approach these are considered in the two case studies shown in boxes 1 and 2 . 


\section{Principles of stopping medicines}

Research, guidelines and training for health professionals in starting new medicines far outweigh those available for stopping medicines. In this relative information vacuum, basic principles can be applied to stop medicines appropriately.

Is the medicine still indicated?

- Check with the patient if they are taking the medicine and their perceived benefits from it. Determine if they have tried to stop the medicine themselves and, if so, what the effect of this was.

- Review the indication, with objective evidence from examination and investigation where appropriate. Consider:

- Was the indication correctly identified (should alternative diagnoses be considered)?

- Does the indication still require treatment? Has it resolved, been controlled or become less relevant to the patient e.g. due to change in life situation?

What is the risk of harm?

- Check with the patient if they are experiencing adverse effects and determine their susceptibility to harms from the medicine (e.g. is this increased by frailty, chronic kidney disease)

- Is the medicine 'high risk' i.e. likely to cause severe adverse drug reactions (e.g. immunosuppression) and/or has a low therapeutic index with risk of toxicity if drug clearance is altered by drug-drug or drug-disease interactions

- Monitor for adverse drug reactions using symptoms, signs and investigations

Assess benefit vs harm

- Determine the patient's overall treatment goals and priorities and discuss how this medicine for this indication and its potential burden and adverse effects fit into this

- The relative degrees of benefit and harm from the medicine will vary but some considerations in decision making are: 
- Low benefit, low risk of harm. Stop the drug to reduce treatment burden. Discuss the pros and cons of stopping the medicine with the patient. Stop unless the patient perceives benefit and cannot be persuaded to do so.

- Low benefit, high risk of harm. Stop the drug to prevent harm.

- High benefit, low risk of harm. Continue the drug to realise benefits

- High benefit, high risk of harm. Consider improving the benefit:harm ratio by prescribing an additional medicine to allow the dose of the harmful medicine to be reduced ('sparing'), substituting the medicine with a safer alternative, and/or prescribing an additional medicine to prevent harm (e.g. gastroprotection with proton pump inhibitor for at risk patients taking nonsteroidal anti-inflammatory drugs)

Stopping medicines

- Sudden cessation. Some medicines can be stopped completely and immediately. These include medicines used for acute indications (e.g. infections) which have resolved and those prescribed for relatively short periods, when dependence is unlikely to have formed (e.g. zopiclone after 5 days)

- Dose reduction. Some medicines require stepped (few stages) or tapered (many stages) dose reduction with careful monitoring for disease reactivation or adverse withdrawal reactions. These include medicines used for diseases that may reactivate or recur and those that cause dependence.

\section{Is there a safe and effective way to wean patients off long-term glucocorticoids?}

For the purpose of this review, 'long term' glucocorticoids are defined as treatment for long enough to cause HPA suppression and therefore to require gradual dose reduction (tapering) to avoid withdrawal reactions. Small studies in healthy volunteers found that short (5-7 days) courses of high dose (40-50mg) prednisolone did not produce sustained HPA suppression [16, 36]. However, adrenal suppression was observed in steroid-naïve COPD patients after taking prednisolone $40 \mathrm{mg}$ daily for 14 days. This persisted in some patients for at least 21 days [37]. Treatment cessation guidelines in the British National Formulary reflect this, identifying patients who have received more than $40 \mathrm{mg}$ prednisolone (or equivalent) daily for more than 
one week or who have received glucocorticoid treatment for more than 3 weeks as requiring gradual treatment withdrawal [38].

\section{Application of stopping principles to long term glucocorticoids}

\section{Is the medicine still indicated?}

Glucocorticoids are used in the treatment of a wide range of inflammatory, immunological, allergic and malignant diseases and in the prevention of graft rejection after transplantation. While some of these conditions resolve after a short course of glucocorticoids, others require longer term treatment to control disease and prevent relapse.

Review of the indication should include checking the diagnosis and that the treatment is appropriate for the condition identified. For example, a patient with 'steroid-resistant' asthma may actually have chronic obstructive pulmonary disease, a condition for which long term systemic glucocorticoid therapy is not normally recommended [39]. Where the diagnosis is correct and glucocorticoid therapy is appropriate, disease control should be assessed as objectively as possible by assessment of symptoms and measurement of disease-specific or non-specific markers. Once the disease is completely suppressed, then slow withdrawal of therapy with close monitoring will determine whether the indication has resolved.

\section{What is the risk of harm?}

Glucocorticoids can be considered high-risk medicines. The adverse drug reactions related to dose and duration of glucocorticoid treatment have been described above.

\section{Assess benefit vs harm}

Where the indication was incorrect or has resolved (low benefit: high risk) the aim should be to stop glucocorticoid treatment. Where treatment is still indicated (high benefit: high risk), strategies to minimise glucocorticoid exposure and harms include: weaning to the lowest dose at which disease is controlled; using steroid sparing medicines or changing to alternative disease modifying drugs; prescribing additional medicines to reduce the risk of harm (e.g. bisphosphonates to reduce the risk of glucocorticoid-induced osteoporosis).

\section{Stopping glucocorticoids}


Long term glucocorticoids must be withdrawn slowly to avoid withdrawal reactions, particularly adrenal insufficiency and crisis. In the UK, patients taking glucocorticoids are advised to carry a Steroid Treatment Card, which alerts patients and healthcare professionals to the risks of adrenal suppression [40]. There are no hard and fast rules about how to taper glucocorticoid therapy. Prescribing guidance, such as that found in the British National Formulary, indicates that treatment should be reduced from starting to 'physiological' doses as rapidly as possible while maintaining control of the underlying disease. Subsequent withdrawal from 'physiological' doses to complete cessation should be done more slowly, at a rate dictated by recovery of endogenous adrenal function to prevent adrenal insufficiency.

In health at times of low physiological stress the adrenal cortex secretes around 5.7 $\mathrm{mg} / \mathrm{m}^{2} /$ day cortisol, equivalent to around $10 \mathrm{mg}$ of hydrocortisone or $2.5 \mathrm{mg}$ prednisolone per day for an average adult [14]. By contrast, treatment guidelines give a 'physiological' cut off equivalent to a dose of $7.5 \mathrm{mg}$ prednisolone per day, below which treatment should be withdrawn slowly to prevent adrenal insufficiency. I was unable to find the reason for this discrepancy in the medical literature, although the higher value $(7.5 \mathrm{mg})$ seems to allow a safety margin for individual variability in cortisol secretion and the stress response.

Tapering of glucocorticoid therapy can be more of an art than a science in clinical practice. As a starting point, generalists may find an example tapering regimen used for patients with inflammatory rheumatic diseases helpful, as shown in table 3 [41]. Specific tapering guidelines have been produced for some conditions. For example guidelines for the management of polymyalgia rheumatica recommend a relatively low starting dose of $15 \mathrm{mg}$ prednisolone with a very slow wean (box 1, case 1), which may take 1-2 years [42], whereas for life- or organthreatening vasculitis, relatively high doses of glucocorticoids (e.g. prednisolone $1 \mathrm{mg} / \mathrm{kg}$ up to $60 \mathrm{mg}$ or IV methyl-prednisolone $250-500 \mathrm{mg}$ ) may be given as part of an immunosuppressive treatment regimen to induce remission, with the dose reduced to $15 \mathrm{mg}$ prednisolone at 12 weeks [43].

\section{Diagnosis and management of new symptoms developing during treatment withdrawal}

Many patients become symptomatic during treatment withdrawal. The challenge is to determine whether this is due to loss of disease control or to physical and/or psychological effects of treatment withdrawal. 


\section{$\underline{\text { Loss of disease control }}$}

As glucocorticoid treatment is weaned, reactivation of disease may be difficult to distinguish from withdrawal effects or re-emergence of symptoms of unrelated conditions. For example, a patient with rheumatic disease who complain of aches and pains as glucocorticoids are withdrawn may be experiencing reactivation of their inflammatory disease, 'pseudorheumatism' of glucocorticoid withdrawal, or renewed awareness of underlying osteoarthritis. Objective assessment of disease activity can be helpful in distinguishing between these differentials. These may be disease-specific, e.g. eosinophil count in Eosinophilic granulomatosis with polyangiitis (EGPA), or non-specific, e.g. measurement of erythrocyte sedimentation rate and C-reactive protein in polymyalgia rheumatica. However, disease markers may not always be definitive in diagnosing relapse. For example, for a patient with inflammatory disease a rise in non-specific (inflammatory markers) may be due to other causes such as infection or may lag behind symptoms, being falsely reassuring.

It is important to identify the cause of new symptoms as treatment is withdrawn as this determines changes to the treatment taper. A disease flare may require an increase in glucocorticoid dose, although a relatively modest increase e.g. to the last effective dose in polymyalgia rheumatica [42], may be enough. Symptoms of glucocorticoid withdrawal syndrome or renewed awareness of underlying conditions can be managed with alternative therapies, such as analgesia or non-steroidal anti-inflammatories for rheumatic symptoms (with a proton pump inhibitor for gastroprotection while on glucocorticoids). Slowing the taper may also allow glucocorticoid withdrawal symptoms to resolve.

Where treatment withdrawal cannot be achieved due to loss of disease control, steroidsparing strategies can be employed to improve the benefit:harm ratio of glucocorticoids. General principles include combining systemic glucocorticoids with topical glucocorticoids (e.g. intraarticular for arthritis, high dose inhaled for asthma) and/or with conventional and biological disease-modifying drugs. Patients should be monitored for long term adverse effects of glucocorticoids (figure 1), with measurement of blood pressure and glucose. Bone protection should be prescribed at the onset of glucocorticoid therapy for those assessed to be at increased risk of fracture [44].Suspecting HPA suppression 
Potency, dose and duration of glucocorticoid treatment are imperfect predictors of adrenal suppression. Pragmatic clinical guidance therefore recommends that adrenal suppression be assumed for patients who have received more than $40 \mathrm{mg}$ prednisolone (or equivalent) daily for more than week or who have received glucocorticoid treatment for more than 3 weeks [45]. Other patients who are likely to have HPA suppression secondary to glucocorticoid therapy include those who have been given repeat doses in the evening, have recently received repeat courses (particularly if longer than 3 weeks) and those who take a new short course of glucocorticoids within 1 year of stopping therapy [45].

For patients 'assumed' to have adrenal suppression, glucocorticoid therapy is gradually tapered. The purpose of the taper is to reduce exogenous glucocorticoid cover gradually, preventing adrenal insufficiency while allowing endogenous glucocorticoid secretion recovery. After relatively short courses of glucocorticoids, HPA suppression can recover in days to weeks. However, where treatment duration has been long enough for adrenal and/or pituitary cell atrophy to occur, recovery may take months to years or may not occur at all, necessitating long term adrenal replacement.

\section{Testing for HPA suppression}

HPA function testing is generally reserved for patients who become symptomatic when withdrawing from glucocorticoids. Its purpose is to distinguish adrenal insufficiency from glucocorticoid withdrawal syndrome (table 1). HPA function is tested by measurement of cortisol. Exogenous glucocorticoids interfere with the cortisol assay, so measurements must be made at least 12 hours after the last dose of hydrocortisone or 24 hours after the last dose of prednisolone. If this period without glucocorticoids is not achievable then treatment should be switched to an equivalent dose of dexamethasone (table 2) before testing as this does not interfere with the cortisol assay.

Patients should initially undergo measurement of 9am cortisol. Values of $<100 \mathrm{mmol} / \mathrm{L}$ indicate cortisol insufficiency and $>450 \mathrm{nmol} / \mathrm{L}$ indicate cortisol sufficiency. Where values are equivocal (100-449nmol/L), a stimulation test should be performed to measure cortisol before and at 30 and 60 minutes after administration of intramuscular synthetic ACTH (short synacthen test). A peak cortisol value of $<550 \mathrm{nmol} / \mathrm{L}$ after stimulation indicates cortisol insufficiency. Check all these reference values with your local laboratory as assays may vary. 


\section{Managing HPA suppression}

Patients diagnosed with cortisol insufficiency require physiological glucocorticoid replacement with hydrocortisone $15-20 \mathrm{mg} /$ day or prednisolone $4-5 \mathrm{mg} /$ day. For some patients, very slow weaning of treatment from these doses over many months may allow full recovery of the HPA axis and eventual cessation of exogenous glucocorticoids. For other patients, recovery does not occur, and lifelong glucocorticoid replacement is required. Withdrawal regimens and retesting should be individualised to each patient. However, as a guide consider retesting for HPA suppression after 3-4 months.

Patients with cortisol insufficiency are at risk of an adrenal crisis, particularly in times of intercurrent illness such as infection, trauma or surgery. They should be warned of the risk and advised to increase (double or treble) their glucocorticoid dose to a minimum of $40 \mathrm{mg}$ hydrocortisone or prednisolone $10 \mathrm{mg}$ if this occurs. Patients should be signposted to 'sick day rules guidance', such as that provided by the Addison's self-help group to help them with this [46].

If HPA suppression is excluded

Glucocorticoid withdrawal syndrome is defined by symptoms that develop as glucocorticoid therapy is withdrawn, despite normal HPA function. If patients have 9 am cortisol $>450 \mathrm{nmol} / \mathrm{I}$ or a normal short synacthen test, with peak cortisol values of $>550 \mathrm{nmol} / \mathrm{L}$ after stimulation, then adrenal insufficiency can be excluded and the patient managed as glucocorticoid withdrawal syndrome.

The physical and psychological effects of glucocorticoid withdrawal can make it difficult for patients to reduce the dose of their glucocorticoids. In case study 2 this is illustrated by patients maintaining themselves on higher doses of glucocorticoids than those prescribed by their physicians. When discussing glucocorticoid tapering, patients should be counselled about the possibility of withdrawal symptoms. If these occur at supraphysiological doses of glucocorticoids, they can be managed by symptomatic treatments (e.g. non-steroidal antiinflammatories with gastroprotection for aches and pains) and by slowing the rate of glucocorticoid taper. If the symptoms are poorly tolerated, the dose of glucocorticoids can be increased to the lowest dose at which they are controlled and treatment tapered very slowly. If symptoms occur at or below 'physiological' glucocorticoid doses, adrenal insufficiency must 
be excluded as described above and repeat testing may be required in patients where this has not been done recently. With time and a very slow treatment taper, glucocorticoid dependence may resolve. Where patients are unable to stop glucocorticoid therapy they should be maintained on the lowest possible dose of treatment. Some endocrinologists recommend switching from prednisolone to hydrocortisone if long term treatment is required because hydrocortisone appears to be associated with a lower risk of fractures [47].

\section{Conclusion}

Although glucocorticoids are effective anti-inflammatory drugs, long term use at even low doses has potential to cause harmful adverse reactions. A general approach to therapy is therefore to use glucocorticoids at as low a dose and for as short a duration as possible to control disease and limit adverse effects. However glucocorticoid withdrawal is also fraught with risk, including loss of disease control and adverse withdrawal effects, including the potential for life-threatening adrenal insufficiency. As indications for glucocorticoid therapy are so diverse and response to withdrawal so complex, blanket guidance will always be imperfect. Healthcare practitioners need to understand and apply the general principles of deprescribing to ensure safe and effective withdrawal of glucocorticoids for individual patients. 


\section{Box 1. Case study 1. Distinguishing between disease reactivation and withdrawal symptoms}

A 70-year-old woman experiences bilateral shoulder and hip pain and stiffness. Her erythocyte sedimentation rate is $70 \mathrm{~mm} / \mathrm{hr}$ and $\mathrm{C}$ reactive protein is $45 \mathrm{mg} / \mathrm{L}$. She is diagnosed with polymyalgia rheumatica and commences treatment with prednisolone $15 \mathrm{mg}$ daily. After 3 weeks her symptoms have disappeared and she is advised to reduce her prednisolone dose to $12.5 \mathrm{mg}$ for 3 weeks, then to $10 \mathrm{mg}$ for 4 weeks, then by $1 \mathrm{mg}$ per month. Nine months later her concerned son tells her GP that she is fatigued and depressed and can't get out of bed or the bath. She has weaned her prednisolone dose to $2 \mathrm{mg}$ daily.

Discussion. Polymyalgia rheumatica (PMR) is an inflammatory musculoskeletal disorder of unknown aetiology, which classically responds well to systemic glucocorticoids. The treatment regimen described here is based on the recommendations of the British Society for Rheumatology and British Health Professionals in Rheumatology [42] and is consistent with the example tapering regimen shown in table 3.

Nine months after starting treatment, this patient has weaned her glucocorticoid dose to sub physiological levels. Her non-specific symptoms could be due to disease reactivation (systemic features of PMR include fatigue, anorexia, weight loss and depression), adrenal insufficiency or glucocorticoid withdrawal syndrome (table 1). The first step in differentiating between these is to measure inflammatory markers to assess for disease reactivation. If inflammatory markers are elevated, then the prednisolone dose should be increased to the previous dose at which symptoms were controlled and the response monitored. If inflammatory markers are not elevated, then disease reactivation is less likely (although not excluded) and adrenal function needs to be assessed by measurement of 9am cortisol, followed by a short synacthen test if values are equivocal. If tests diagnose or fail to exclude adrenal insufficiency, the prednisolone dose should be increased to $4-5 \mathrm{mg}$ to ensure physiological replacement and the patient given the appropriate advice about increasing the dose if unwell. This can then be weaned very slowly over a long period with repeat testing to see if adrenal function recovers. If adrenal function is normal then an increase in prednisolone dose to control glucocorticoid withdrawal symptoms may be required, with a very slow wean to give them time to resolve. 


\section{Box 2. Case study 2. Patients can find it impossible to withdraw from glucocorticoids}

A 69-year-old man with advanced chronic obstructive pulmonary disease (COPD), anxiety and depression is seen by his GP to determine whether long term glucocorticoids can be withdrawn. The patient takes prednisolone $20 \mathrm{mg}$ daily and feels unable to reduce the dose because of breathlessness. His lung function shows severe irreversible airflow obstruction (Forced expiratory volume in one second $\left(\mathrm{FEV}_{1}\right)$ 22\% predicted, $\mathrm{FEV}_{1}$ :Forced vital capacity (FVC) 0.4 with no evidence of bronchodilator reversibility). His weight has increased by $10 \mathrm{~kg}$ in the past year, he has osteoporosis with a vertebral compression fracture and his random blood glucose is $12.3 \mathrm{mmol} / \mathrm{L}$.

\section{Discussion}

Long term systemic glucocorticoid therapy is not normally recommended for the treatment of COPD [39]. Some patients with advanced COPD may find it difficult to stop systemic glucocorticoids prescribed for exacerbations, particularly where exacerbations are frequent. If patients cannot stop glucocorticoids, the dose should be kept as low as possible and the focus should be on preventing complications.

This patient feels breathless whenever he tries to reduce the dose of his prednisolone. There is little evidence that long-term systemic glucocorticoids improve lung physiology in people with stable COPD [48], so this may be due to 'psychological dependence' on glucocorticoids. A holistic approach would include: medical review to look for other causes of breathlessness such as heart failure; optimisation of COPD management (including smoking cessation, pulmonary rehabilitation and inhaler review); consideration of advanced COPD therapies (e.g. lung volume reduction); symptom management and psychological support. Glucocorticoids should be weaned to the lowest tolerated dose and measures to ameliorate the adverse effects of long term glucocorticoids including osteoporosis (e.g. bisphosphonate treatment) and diabetes mellitus (e.g. low sugar diet, oral hypoglycaemic treatment) should be implemented to reduce the risk of harm. 
Acknowledgement

None

Conflict of interest

None

Funding

None 


\section{References}

1. Laugesen K, Jørgensen JOL, Petersen I, Sørensen HT. Fifteen-year nationwide trends in systemic glucocorticoid drug use in Denmark. Eur J Endocrinol. 2019;181(3):267-273.

2. Prescription cost analysis. England 2018. https://digital.nhs.uk/data-andinformation/publications/statistical/prescription-cost-analysis/2018 Last accessed $19 / 9 / 20$

3. Rhen T, Cidlowski JA. Antiinflammatory action of glucocorticoids--new mechanisms for old drugs. N Engl J Med. 2005;353(16):1711-1723.

4. Aronson JK, Ferner RE. Joining the DoTS: new approach to classifying adverse drug reactions. BMJ. 2003 Nov 22;327:1222-5.

5. Judd LL, Schettler PJ, Brown ES, Wolkowitz OM, Sternberg EM, Bender BG, Bulloch K, Cidlowski JA, de Kloet ER, Fardet L, Joëls M, Leung DY, McEwen BS, Roozendaal B, Van Rossum EF, Ahn J, Brown DW, Plitt A, Singh G. Adverse consequences of glucocorticoid medication: psychological, cognitive, and behavioral effects. Am J Psychiatry. 2014;171(10):1045-51.

6. Waljee AK, Rogers MA, Lin P, Singal AG, Stein JD, Marks RM, Ayanian JZ, Nallamothu BK. Short term use of oral corticosteroids and related harms among adults in the United States: population based cohort study. BMJ. 2017;357:j1415.

7. Curtis JR, Westfall AO, Allison J, Bijlsma JW, Freeman A, George V, Kovac SH, Spettell CM, Saag KG. Population-based assessment of adverse events associated with long-term glucocorticoid use. Arthritis Rheum. 2006;55(3):420-6.

8. Van Staa TP, Leufkens HG, Abenhaim L, Zhang B, Cooper C. Use of oral corticosteroids and risk of fractures. J Bone Miner Res. 2000;15(6):993-1000.

9. Laan RF, van Riel PL, van de Putte LB, van Erning $L$, van't Hof MA, Lemmens JA. Low-dose prednisone induces rapid reversible axial bone loss in patients with rheumatoid arthritis. A randomized, controlled study. Ann Intern Med. 1993;119(10):963-968.

10. MacGregor AJ, Dhillon VB, Binder A, Forte CA, Knight BC, Betteridge DJ, Isenberg DA. Fasting lipids and anticardiolipin antibodies as risk factors for vascular disease in systemic lupus erythematosus. Ann Rheum Dis. 1992;51(2):152-5

11. Huscher D, Thiele K, Gromnica-Ihle E, Hein G, Demary W, Dreher R, Zink A, Buttgereit F. Dose-related patterns of glucocorticoid-induced side effects. Ann Rheum Dis. 2009;68(7):1119-24. 
12. Da Silva JA, Jacobs JW, Kirwan JR, Boers M, Saag KG, Inês LB, de Koning EJ, Buttgereit F, Cutolo M, Capell H, Rau R, Bijlsma JW. Safety of low dose glucocorticoid treatment in rheumatoid arthritis: published evidence and prospective trial data. Ann Rheum Dis. 2006;65(3):285-93.

13. Wei L, MacDonald TM, Walker BR. Taking glucocorticoids by prescription is associated with subsequent cardiovascular disease. Ann Intern Med. 2004;141(10):764-770.

14. Esteban NV, Loughlin T, Yergey AL, Zawadzki JK, Booth JD, Winterer JC, Loriaux DL. Daily cortisol production rate in man determined by stable isotope dilution/mass spectrometry. J Clin Endocrinol Metab. 1991;72(1):39-45.

15. Mosteller RD. Simplified calculation of body-surface area. N Eng/ J Med 1987;317:1098

16. Streck, W.F.; Lockwood, D.H. Pituitary adrenal recovery following short-term suppression with corticosteroids. Am. J. Med. 1979, 66, 910-914

17. Nicolaides NC, Pavlaki AN, Maria Alexandra MA, Chrousos GP. Glucocorticoid Therapy and Adrenal Suppression. [Updated 2018 Oct 19]. In: Feingold KR, Anawalt B, Boyce A, et al., editors. Endotext [Internet]. South Dartmouth (MA): MDText.com, Inc.; 2000-. Available from: https://www.ncbi.nlm.nih.gov/books/NBK279156/ Last accessed 19/9/20

18. Jasani MK, Boyle JA, Greig WR, Dalakos TG, Browning MC, Thompson A, Buchanan WW. Corticosteroid-induced suppression of the hypothalamo-pituitary-adrenal axis: observations on patients given oral corticosteroids for rheumatoid arthritis. Q J Med. 1967 Jul;36(143):261-76.

19. Mendoza-Cruz, A.C.; Wargon, O.; Adams, S.; Tran, H.; Verge, C.F. Hypothalamic-pituitaryadrenal axis recovery following prolonged prednisolone therapy in infants. J. Clin. Endocrinol. Metab. 2013, 98, E1936-E1940.

20. Joseph RM, Hunter AL, Ray DW, Dixon WG. Systemic glucocorticoid therapy and adrenal insufficiency in adults: A systematic review. Semin Arthritis Rheum. 2016;46(1):133-141.

21. Broersen LH, Pereira AM, Jørgensen JO, Dekkers OM. Adrenal Insufficiency in Corticosteroids Use: Systematic Review and Meta-Analysis. J Clin Endocrinol Metab. 2015;100(6):2171-2180.

22. Laugesen K, Petersen I, Sørensen HT, Jørgensen JOL. Clinical indicators of adrenal insufficiency following discontinuation of oral glucocorticoid therapy: A Danish population-based self-controlled case series analysis. PLoS One. 2019;14(2):e0212259. 
23. Giordano R, Guaraldi F, Mazzoli M, Ghigo E. Do glucocorticoids induce addiction in humans?. J Endocrinol Invest. 2017;40(8):881-883

24. Hochberg Z, Pacak K, Chrousos GP. Endocrine withdrawal syndromes. Endocr Rev. 2003;24(4):523-38

25. Fardet L, Nazareth I, Whitaker HJ, Petersen I: Severe neuropsychiatric outcomes following discontinuation of long-term glucocorticoid therapy: a cohort study. J Clin Psychiatry 2013; 74:e281-e286

26. Goldfarb EV, Sinha R. Drug-Induced Glucocorticoids and Memory for Substance Use. Trends Neurosci. 2018 Nov;41(11):853-868.

27. Anfinson TJ, Channappa C, Vo HT. Drug dependence involving prednisone: two cases and a review of the literature. Psychopharmacol Bull. 2008;41(1):154-63.

28. Huizenga NA, Koper JW, De Lange $\mathrm{P}$, et al. A polymorphism in the glucocorticoid receptor gene may be associated with and increased sensitivity to glucocorticoids in vivo. J Clin Endocrinol Metab. 1998;83(1):144-151.

29. Saberi P, Phengrasamy T, Nguyen DP. Inhaled corticosteroid use in HIV-positive individuals taking protease inhibitors: a review of pharmacokinetics, case reports and clinical management. HIV Med. 2013 Oct;14(9):519-29.

30. Daley-Yates PT. Inhaled corticosteroids: potency, dose equivalence and therapeutic index. Br J Clin Pharmacol. 2015;80(3):372-380.

31. British National Formulary. Glucocorticoid and mineralocorticoid activity. https://bnf.nice.org.uk/treatment-summary/glucocorticoid-therapy.html Last accessed $19 / 9 / 20$

32. British National Formulary. Topical corticosteroids. https://bnf.nice.org.uk/treatmentsummary/topical-corticosteroids.html Last accessed 19/9/20

33. Robson JC, Dawson J, Cronholm PF, Ashdown S, Easley E, Kellom KS, Gebhart D, Lanier G, Milman N, Peck J, Luqmani RA, Shea JA, Tomasson G, Merkel PA. Patient perceptions of glucocorticoids in anti-neutrophil cytoplasmic antibody-associated vasculitis. Rheumatol Int. 2018;38(4):675-682.

34. Prasad GV, Nash MM, McFarlane PA, Zaltzman JS. Renal transplant recipient attitudes toward steroid use and steroid withdrawal. Clin Transplant. 2003;17(2):135-139.

35. Hashimoto S, Brinke AT, Roldaan AC, van Veen IH, Moller GM, Sont JK, Weersink EJM, can der Zee JS, Braunstahl G-J, Zwinderman AH, Sterk PJ, Bel EH. Internet-based tapering of 
oral corticosteroids in severe asthma: a pragmatic randomised controlled trial Thorax 2011;66:514-520.

36. Carella MJ, Srivastava LS, Gossain VV, Rovner DR. Hypothalamic-pituitary-adrenal function one week after a short burst of steroid therapy. J Clin Endocrinol Metab. 1993;76(5):11881191.

37. Schuetz P, Christ-Crain M, Schild U, Süess E, Facompre M, Baty F, Nusbaumer C, Brutsche M, Müller B. Effect of a 14-day course of systemic corticosteroids on the hypothalamicpituitary-adrenal-axis in patients with acute exacerbation of chronic obstructive pulmonary disease. BMC Pulm Med. 2008;8:1

38. British National Formulary. Prednisolone. Treatment Cessation. https://bnf.nice.org.uk/drug/prednisolone.html\#treatmentCessationInformation Last accessed 19/9/20

39. NICE guideline [NG115] Chronic obstructive pulmonary disease in over 16s: diagnosis and management https://pathways.nice.org.uk/pathways/chronic-obstructive-pulmonarydisease\#path=view\%3A/pathways/chronic-obstructive-pulmonary-disease/stable-copdoral-therapy.xml\&content=view-node\%3Anodes-corticosteroids Last accessed 19/9/20

40. British National Formulary. Prednisolone. Steroid treatment card.

https://bnf.nice.org.uk/drug/prednisolone.html\#patientAndCarerAdvice. Last accessed $19 / 9 / 20$

41. Furst DE, Matteson EL, Ramirez Curtis M. Glucocorticoid withdrawal. https://www.uptodate.com/contents/glucocorticoid-withdrawal Last accessed 19/9/20

42. NICE clinical knowledge summaries. Scenario: Management of polymyalgia rheumatica Last accessed 19/9/20 https://cks.nice.org.uk/polymyalgiarheumatica\#!scenarioRecommendation

43. Ntatsaki E, Carruthers D, Chakravarty K, D'Cruz D, Harper L, Jayne D, Luqmani R, Mills J, Mooney J, Venning M, Watts RA; on behalf of the BSR and BHPR Standards, Guidelines and Audit Working Group, BSR and BHPR guideline for the management of adults with ANCA-associated vasculitis, Rheumatology, Volume 53, Issue 12, December 2014, Pages 2306-2309

44. Compston J, Cooper A, Cooper C, Gittoes N, Gregson C, Harvey N, Hope S, Kanis JA, McCloskey EV, Poole KES, Reid DM, Selby P, Thompson F, Thurston A, Vine N; National 
Osteoporosis Guideline Group (NOGG). UK clinical guideline for the prevention and treatment of osteoporosis. Arch Osteoporos. 2017 Dec;12(1):43.

45. British National Formulary. Prednisolone. Treatment Cessation. https://bnf.nice.org.uk/drug/prednisolone.html\#treatmentCessationInformation Last accessed $19 / 9 / 20$

46. Addison's self-help group. Newly diagnosed - Sick day rules https://www.addisonsdisease.org.uk/newly-diagnosed-sick-day-rules Last accessed $19 / 9 / 20$

47. Vestergaard P, Rejnmark L, Mosekilde L. Fracture risk associated with different types of oral corticosteroids and effect of termination of corticosteroids on the risk of fractures. Calcif Tissue Int. 2008;82(4):249-257.

48. Walters JAE, Walters EH, Wood-Baker R. Oral corticosteroids for stable chronic obstructive pulmonary disease. Cochrane Database of Systematic Reviews 2005, Issue 3. Art. No.: CD005374. 
Table 1. Comparison of adrenal insufficiency and glucocorticoid withdrawal syndrome in patients withdrawing from long term glucocorticoids

\begin{tabular}{|c|c|c|}
\hline & Adrenal insufficiency & $\begin{array}{l}\text { Glucocorticoid withdrawal } \\
\text { syndrome }\end{array}$ \\
\hline Symptoms & $\begin{array}{l}\text { anorexia, fatigue, nausea, } \\
\text { vomiting, dyspnea, fever, } \\
\text { arthralgia, myalgia, orthostatic } \\
\text { hypotension, dizziness, fainting, } \\
\text { circulatory collapse }\end{array}$ & $\begin{array}{l}\text { anorexia, nausea, emesis, weight } \\
\text { loss, fatigue, myalgias, arthralgias, } \\
\text { weakness, headache, abdominal } \\
\text { pain, lethargy, postural } \\
\text { hypotension, fever, skin } \\
\text { desquamation, tachycardia, } \\
\text { emotional lability, delirium, } \\
\text { psychotic states }\end{array}$ \\
\hline $\begin{array}{l}\text { Steroid } \\
\text { dosage }\end{array}$ & $\begin{array}{l}\text { Symptomatic below 'physiological' } \\
\text { doses }\end{array}$ & $\begin{array}{l}\text { Symptoms can occur at } \\
\text { supraphysiological doses of } \\
\text { glucocorticoids }\end{array}$ \\
\hline HPA testing & $\begin{array}{l}\text { Cortisol insufficiency } \\
\text { 9am cortisol <100nmol/L } \\
\text { and/or } \\
\text { Peak cortisol after synacthen } \\
\text { stimulation } \leq 550 \mathrm{nmol} / \mathrm{L}\end{array}$ & $\begin{array}{l}\text { Normal HPA function } \\
9 \text { am cortisol }>450 \mathrm{nmol} / \mathrm{L} \\
\text { and/or } \\
\text { Peak cortisol after synacthen } \\
\text { stimulation }>550 \mathrm{nmol} / \mathrm{L}\end{array}$ \\
\hline $\begin{array}{l}\text { Risk of } \\
\text { adrenal crisis }\end{array}$ & Yes & No \\
\hline Management & $\begin{array}{l}\text { - Reduce glucocorticoids to } \\
\text { 'physiological' dose } \\
\text { - Long term replacement with } \\
\text { hydrocortisone } 15-20 \mathrm{mg} / \mathrm{day} \\
\text { or prednisolone } 4-5 \mathrm{mg} / \mathrm{day} \\
\text { - Increase glucocorticoids during } \\
\text { intercurrent illness } \\
\text { - Very slow wean over the long } \\
\text { term to allow HPA axis recovery }\end{array}$ & $\begin{array}{l}\text { - Reduce glucocorticoids to the } \\
\text { lowest possible dose that } \\
\text { controls symptoms } \\
\text { - Then withdraw very slowly over } \\
\text { months } \\
\text { - No need to increase } \\
\text { glucocorticoids during } \\
\text { intercurrent illness } \\
\text { - Consider retesting HPA axis if } \\
\text { glucocorticoid wean is very } \\
\text { prolonged and difficult }\end{array}$ \\
\hline
\end{tabular}


Table 2. Relative potency of synthetic glucocorticoids

\begin{tabular}{|c|c|c|c|c|}
\hline Corticosteroid & $\begin{array}{l}\text { Routes of } \\
\text { administration }\end{array}$ & $\begin{array}{l}\text { Relative } \\
\text { glucocorticoid } \\
\text { receptor } \\
\text { binding affinity }\end{array}$ & $\begin{array}{l}\text { Systemic } \\
\text { dosage } \\
\text { equivalence }\end{array}$ & $\begin{array}{l}\text { Potency classification } \\
\text { when used topically at } \\
\text { the concentrations } \\
\text { (weight/volume) } \\
\text { shown }\end{array}$ \\
\hline Fluticasone furoate & Inhaled & 2989 & & \\
\hline Clobetasol proprionate & Topical & & & Very potent $0.05 \%$ \\
\hline Fluocinolone Acetonide & Topical & & & $\begin{array}{l}\text { Potent }-0.025 \% \\
\text { Moderate } 0.00625 \%\end{array}$ \\
\hline Mometasone furoate & Inhaled, topical & 2100 & & Potent $0.1 \%$ \\
\hline Fluticasone propionate & Inhaled, topical & 1775 & & Potent $0.05 \%$ \\
\hline Beclomethasone dipropionate & Inhaled, topical & 1345 & & Potent $0.025-0.05 \%$ \\
\hline Betamethasone diproprionate & Oral, Topical & & & Potent $0.05 \%$ \\
\hline Fludroxycortide & Topical & & & Moderate $0.0125 \%$ \\
\hline Betamethasone valerate & Topical & & & $\begin{array}{l}\text { Potent } 0.1 \% \\
\text { Moderate } 0.025 \%\end{array}$ \\
\hline Hydrocortisone butyrate & Topical & & & Potent $0.1 \%$ \\
\hline Diflucortolone valerate & Topical & & & $\begin{array}{l}\text { Very potent } 0.3 \% \\
\text { Potent } 0.1 \%\end{array}$ \\
\hline Clobetasone butyrate & Topical & & & Moderate $0.05 \%$ \\
\hline Ciclesonide (des-CIC) & Inhaled & 1200 & & \\
\hline Budesonide & Inhaled & 935 & & \\
\hline Triamcinolone acetonide & Inhaled & 233 & $4 \mathrm{mg}$ & \\
\hline Flunisolide & Inhaled & 190 & & \\
\hline $\begin{array}{l}\text { Betamethasone sodium } \\
\text { phosphate }\end{array}$ & Oral, injection & & $0.75 \mathrm{mg}$ & \\
\hline Dexamethasone & Oral, injection & 100 & $0.75 \mathrm{mg}$ & \\
\hline Methylprednisolone & Oral, injection & & $4 \mathrm{mg}$ & \\
\hline Prednisolone & Oral & 12 & $5 \mathrm{mg}$ & \\
\hline Hydrocortisone (cortisol) & $\begin{array}{l}\text { Oral, injection, } \\
\text { topical }\end{array}$ & $\sim 2.5$ & $20 \mathrm{mg}$ & Mild 0.1-2.5\% \\
\hline
\end{tabular}

The table shows synthetic glucocorticoids administered systemically (oral or injection), topically and/or by inhalation ranked as far as possible from highest to lowest in terms of 
potency using glucocorticoid receptor binding affinity [4], systemic dosage equivalence [5] and/or topical steroid potency classification [6]. 
Table 3. An example tapering regimen for reducing glucocorticoid dose in patients with inflammatory rheumatic diseases [41]

\begin{tabular}{|l|l|}
\hline $\begin{array}{l}\text { Dose (prednisolone or } \\
\text { equivalent) }\end{array}$ & Taper \\
\hline$>40 \mathrm{mg}$ & $5-10 \mathrm{mg} /$ day every $1-2$ weeks \\
\hline $20-40 \mathrm{mg}$ & $5 \mathrm{mg} /$ day every $1-2$ weeks \\
\hline $10-20 \mathrm{mg}$ & $2.5 \mathrm{mg} /$ day every $2-3$ weeks \\
\hline $5-10 \mathrm{mg}$ & $1 \mathrm{mg} /$ day every $2-4$ weeks \\
\hline$\leq 5 \mathrm{mg}$ & $\begin{array}{l}0.5 \mathrm{mg} / \text { day every } 2-4 \text { weeks } \\
\text { (can be achieved by alternating daily doses } \\
\text { e.g. } 5 \text { mg on day } 1,4 \text { mg on day } 2 \text { etc) }\end{array}$ \\
\hline
\end{tabular}




\section{Figure legends}

Figure 1. Adverse effects of glucocorticoids - dose relatedness and timing

The adverse effects of systemic glucocorticoids are plotted approximately at the earliest time after treatment initiation (in months) and the lowest dose (prednisolone equivalent) at which they have been reported to occur. For example, neuropsychiatric effects occur early in people taking high dose treatment whereas cardiovascular disease is not increased in people taking prednisolone unless the dose has been $>7.5 \mathrm{mg}$ for $>1$ year. Even very low dose glucocorticoid treatment can cause adverse effects if taken over a long period of time. Adverse reactions where the dose relatedness and timing of adverse effects is particularly variable due to differences in patient susceptibility (such as hyperglycaemia and hypokalaemia) are not included in this plot.

Each reference relates to all the adverse effects included in the box

Figure 2. Schematic illustrating relationship of glucocorticoid dose to disease control and adverse drug reactions

Disease reactivation, adrenal insufficiency, glucocorticoid withdrawal syndrome and psychological dependence can all contribute to new symptoms as glucocorticoid therapy is withdrawn. The dosage at which these symptoms develop can help to identify the most likely cause. 


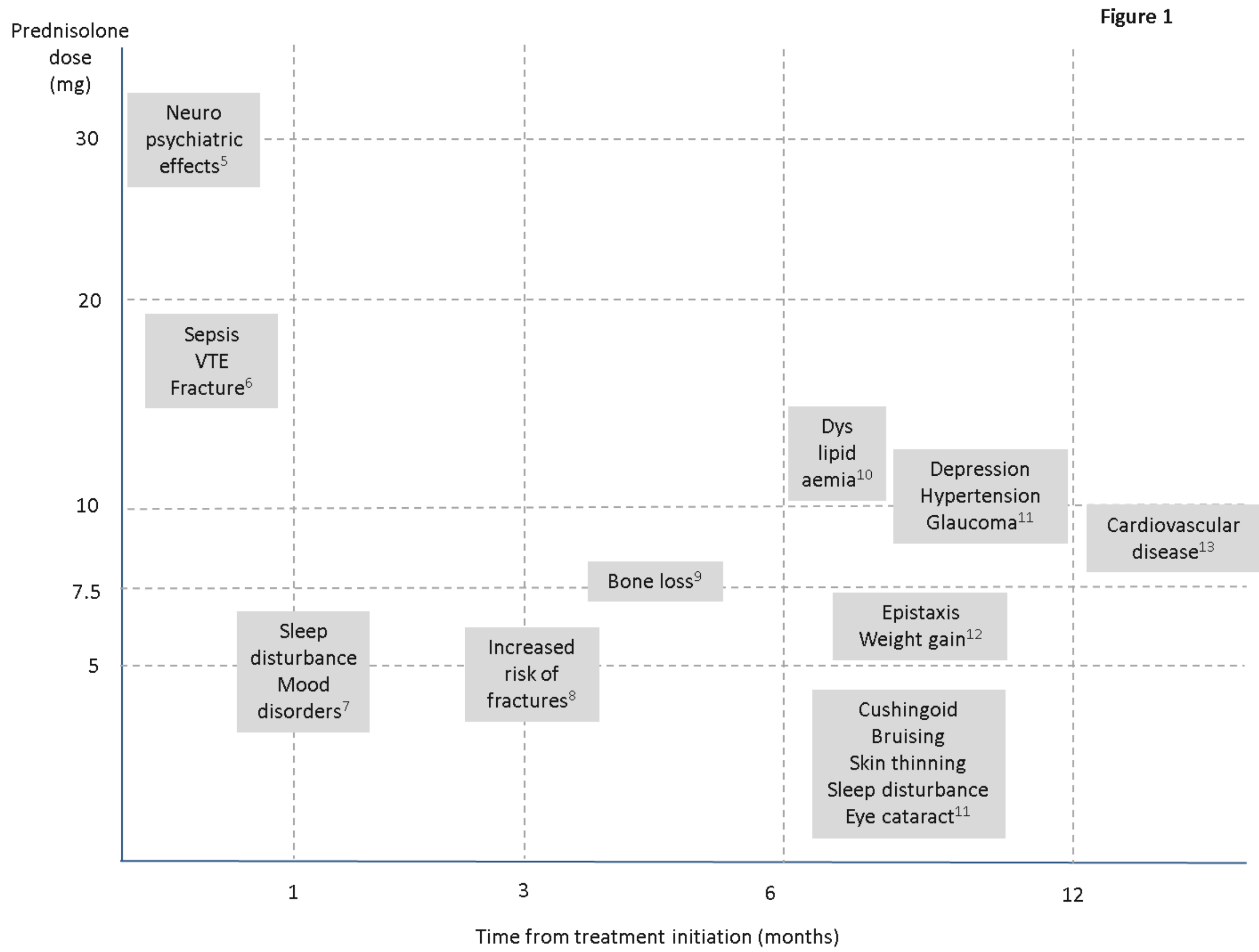




\section{Figure 2}

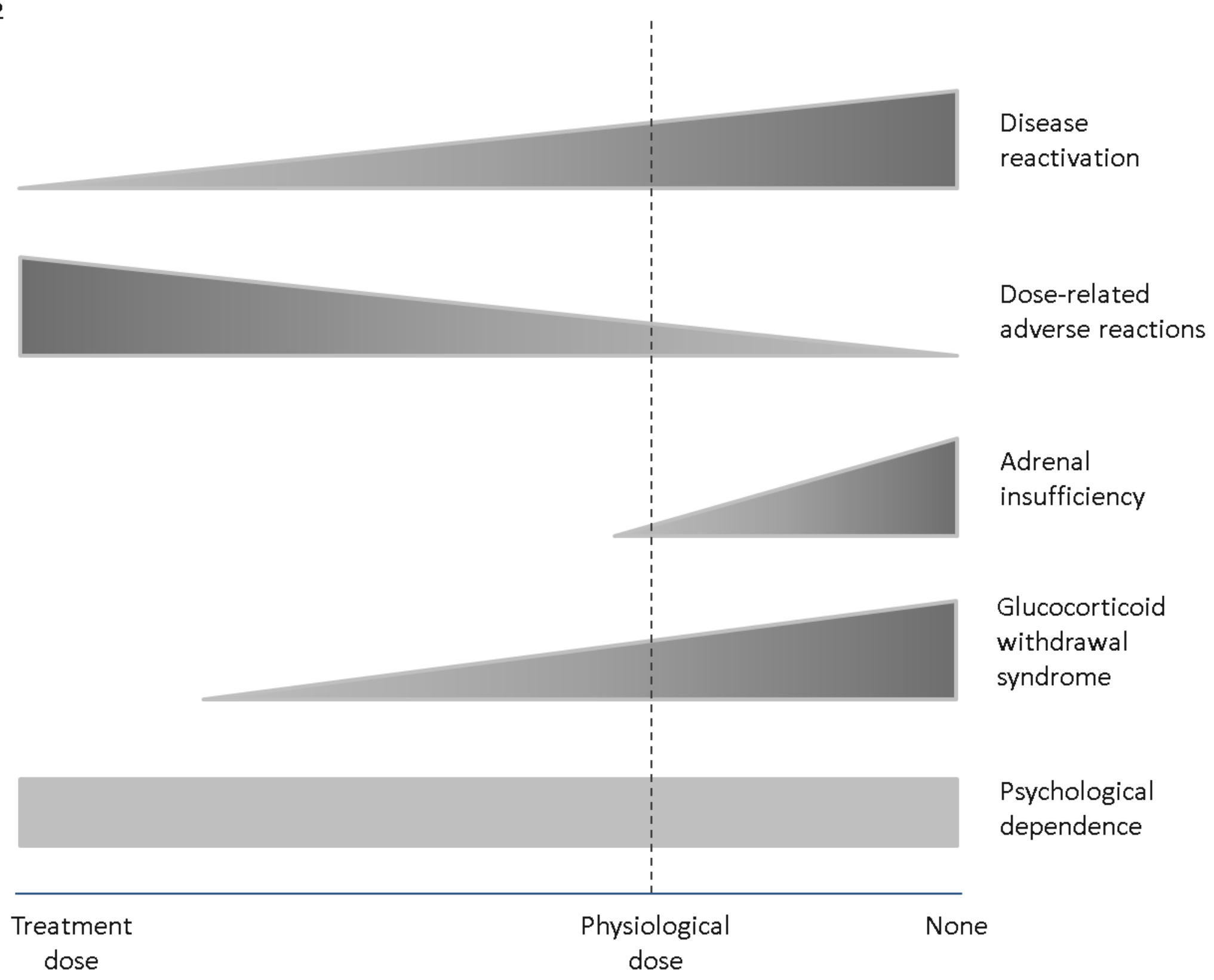

Glucocorticoid dose 